\title{
Por uma sociologia da suspensão: da recursividade entre concepções e práticas
}

\author{
Joana Elisa Röwer ${ }^{1}$ \\ Jorge Luiz da Cunha ${ }^{2}$ \\ Maria da C. F. B. S. Passeggi ${ }^{3}$
}

\section{Introdução}

Narrar a própria experiência provoca estranhamentos do saber sobre o senso comum e pode possibilitar conscientizações, nas relações entre História, estrutura social e trajetórias individuais. Nesse sentido, indagamos como a imaginação sociológica, o estranhamento e a desnaturalização, tidos como objetivos do ensino de Sociologia, se aproximam das narrativas autobiográficas como dispositivos de formação, estabelecendo um diálogo entre ensino de Sociologia e o campo da Pesquisa (Auto)biográfica em Educação. Dialogamos com diferentes perspectivas teóricas no intuito de observar que compreensões distintas sobre a constituição social do indivíduo problematizam o próprio sentido do ensino de Sociologia na escola.

Este trabalho põe em diálogo as orientações legais sobre as especificidades da Sociologia e as narrativas autobiográficas como dispositivos de formação; discute a fundamentação epistemológica do trabalho com narrativas autorreferenciais nas aulas de Sociologia; e, apresenta e analisa a aplicação de uma proposta de ensino de Sociologia a partir de narrativas autobiográficas de alunos do $1^{\circ}$ ano do ensino médio. Sendo que a análise dos relatos, decorrentes da proposta, foi realizada com base na Análise Textual

\footnotetext{
${ }^{1}$ Doutoranda em Educação (UFSM). joanarower@gmail.com

2 Professor Titular da Universidade Federal de Santa Maria. (UFSM). jlcunha11@yahoo.com.br

${ }^{3}$ Pesquisadora Pq2-CNPq. Professora Titular do Centro de Educação da Universidade Federal do Rio Grande do Norte (UFRN). mariapasseggi@gmail.com
} 
Discursiva (ATD) de Moraes (2003) e Moraes e Galiazzi (2007), cujas unidades de análise também foram fundamentadas no conceito de construção e reconstrução da aprendizagem de Dewey (2010).

Estranhar e desnaturalizar o que se sabe sobre si, o que se escuta sobre si e deixar em suspensão para novas reorganizações, para construções e reconstruções da aprendizagem e, principalmente, para uma prática de questionamentos em que a interrogação não versa somente sobre o outro, mas sobre si na relação com outros. Eis aí talvez uma tarefa da educação em que a Sociologia adquire importância na formação dos jovens. Desse modo, o que sustentamos é a centralidade da relação sociedadeindivíduo no ensino de ciências sociais/sociologia na educação escolar. $O$ que sinalizamos é a possibilidade do desenvolvimento da habilidade de suspender-se.

\section{Reflexões sobre o ensino de sociologia e narrativas autobiográficas como dispositivos de formação}

Em relação às possíveis contribuições da Sociologia no ensino médio as Orientações Curriculares Nacionais OCN (2006) indicam: aproximar o jovem da linguagem sociológica; estruturar, sintetizar e codificar os debates de temáticas sociais de relevância histórica ou contemporânea; modificar concepções de mundo pela compreensão de diversas pesquisas sobre o social que revelam outras realidades e interpretações; e, reconstruir e desconstruir modos de pensar. Em relação aos objetivos as OCN (2006), pontuam como papel central da Sociologia, além da contribuição na formação da criticidade e da cidadania, expostas pelos Parâmetros Curriculares Nacionais para o Ensino Médio (PCNEM, 1999), o desenvolvimento dos processos de estranhamento e desnaturalização.

Segundo as OCN (2006) o estranhamento significa, de modo geral, pôr em evidência os fatos cotidianos e interpretá-los como objetos de estudo da Sociologia ao compreender as causas, as regularidades e como estes influenciam os indivíduos. A desnaturalização significa compreender as regras, as normas, os valores, as instituições sociais no seu processo histórico e dinâmico. As OCN (2006, p. 107) afirmam que "só é possível tomar certos fenômenos como objeto da Sociologia na medida em que sejam 
submetidos a um processo de estranhamento, que sejam colocados em questão, problematizados".

Carvalho Filho (2014) ao discorrer sobre a Sociologia no ensino médio situa, como as OCN (2006), o estranhamento e a desnaturalização como seus princípios epistemológicos que a caracterizam como uma ciência compreensiva e explicativa. $\mathrm{O}$ autor escreve que o estranhamento significa questionar "o que faz isso ser assim e não de outra forma? Essa postura suscita explicação, e a busca da explicação possibilita consequentemente a desnaturalização do mundo das coisas" (CARVALHO FILHO, 2014, p. 72).

O livro Sociologia (2010) também pontua como princípios epistemológicos da Sociologia no ensino médio o desenvolvimento do estranhamento e da desnaturalização. Há no texto um delineamento e um reforço desses princípios como uma "disposição necessária" no dizer de Moraes (2010, p.46). Contudo, compreendemos que estranhamentos e desnaturalizações são possibilidades de sentidos, objetivos e efeitos da Sociologia como disciplina escolar e que necessitam da reflexão sobre a relação entre contextos e condicionantes sociais/culturais e biografias individuais.

Há no livro Sociologia (2010) uma subseção dedicada à definição destes conceitos-processos o que revela a ênfase dada a eles. Moraes e Guimarães (2010) que discorrem sobre o estranhamento e a desnaturalização, pontuam que estranhar situações cotidianas é uma tarefa imperativa às Ciências Sociais para transpor interpretações decorrentes do senso comum, e realizar os objetivos de análise da realidade de forma sistemática.

Estranhar e desnaturalizar são processos interligados, pois se estranhar é pôr em evidência ao perguntar "Por quê?", desnaturalizar significa procurar compreender as interpretações e explicações sobre as relações sociais de modo não naturalizado, ou seja, compreender a historicidade dos fenômenos sociais e compreendê-los como decorrentes das razões humanas, das ações humanas, isto é, como produtos culturais-sociais. O estranhamento e a desnaturalização recaem tanto sobre os fenômenos sociais como sobre as explicações desses fenômenos, assim proporciona estados de suspensão de saberes e procura por outras compreensões, em processos sempre dinâmicos.

Gilberto Velho (1978) demonstra que não é a proximidade ou a distância que produz familiaridade ou exotismo, naturalidade ou estranhamento, necessariamente, e 
que estes simbolizem compreensões e incompreensões. Afirma ainda que em nossa sociedade complexa, hierarquizada, composta de estereótipos sociais e anonimatos, plural e midiática, a noção de familiaridade e exotismo é relativizada. O próprio grau de familiaridade e exotismo entre grupos e pessoas não é homogêneo, na medida em que a simples proximidade não significa conhecer os processos de funcionamento. Velho (1978) situa a familiaridade como um certo tipo de apreensão da realidade, como uma forma de interpretação e, por isso, de produção de conhecimento, assim, as pessoas no seu cotidiano também interpretam e produzem familiaridades e estranhamentos, o que varia é a base da argumentação e da interpretação. O estranhamento pode ocorrer sobre apreensões, interpretações da cotidianidade, sobre argumentações embasadas no senso comum.

Debruçar-se sobre o senso comum é condição para compreender o indivíduo e os grupos nos seus modos de concepções e ações nos espaços que constituem e que atravessam. A filosofia da práxis de Gramsci (2004); a sociologia do conhecimento de Berger e Luckman (2004); a teoria crítica pós-moderna e o projeto de emancipação social de Boaventura de Souza Santos (1989, 2002, 2009); e, a antropologia interpretativa de Geertz (2012) são diferentes perspectivas teóricas que tomaram o senso comum como objeto de análise.

De forma breve apenas demarcamos que se para Berger e Luckman (2004) o senso comum se caracteriza por ser um conhecimento evidente, naturalizado, compartilhado, que constitui um acervo social de conhecimento, transmitido de geração a geração, que direciona o indivíduo na vida cotidiana e que possibilita a vida em interação; para Geertz (2012) há a necessidade de repensar a distinção do senso comum como uma mera apreensão da realidade ou como uma sabedoria coloquial. Para Geertz (2012) esta categoria é um produto histórico e, assim, o senso comum não é mera apreensão da realidade, mas interpretação da realidade imediata que proporciona explicações aos fatos da vida, tendo a pretensão da veracidade. Nesta perspectiva, o senso comum é interpretado como um sistema cultural, pois dotado de significados.

Em Gramsci (2004) e em Santos (1989, 2002, 2009) há um projeto de emancipação humana através da compreensão e da transformação/superação do conhecimento do senso comum. "A filosofia da práxis não busca manter os 'simples' na sua filosofia primitiva do senso comum, mas busca, ao contrário, conduzi-los a uma 
concepção de vida superior" (GRAMSCI, 2004, p. 103). Isto também porque no senso comum encontra-se difundida a visão de mundo das classes dominantes. A reforma intelectual e moral e a elevação das massas passa pela crítica ao senso comum, assim como, pela filosofia dominante. A elevação cultural das massas passa pela construção de um novo senso comum, pelo rompimento do isolamento entre intelectuais e povo, da dicotomia dominantes/dominados em que as concepções de mundo próprias das classes subalternas, popularizam-se, difundem-se atuando sobre o senso comum (MOCHCOVITCH, 2001).

Já Santos (1989, 2002, 2009) percebe no senso comum uma dimensão utópica, libertadora e uma virtude antecipatória na sua possibilidade de reinvenção para a emancipação através do diálogo com a ciência pós-moderna, com a aplicação edificante da ciência. A positividade do senso comum também é dada pela sua possibilidade de transformação. "Deixado a si mesmo, o senso comum, é conservador, e pode legitimar prepotências, mas interpenetrado pelo conhecimento científico pode estar na origem de uma nova racionalidade" (SANTOS, 2009, p. 89-90).

A compreensão sobre o senso comum é importante, na medida em que, se a realidade como vivida é a base da argumentação do senso comum que constitui os modos de interpretação das pessoas na cotidianidade, então o estranhamento e a desnaturalização no ensino de sociologia na educação básica pode partir do senso comum e das vivências individuais. A possibilidade de estranhar e desnaturalizar o senso comum através dos relatos autobiográficos remete a estranhar e desnaturalizar práticas cotidianas. E o estranhamento e a desnaturalização compreendidos como atos pedagógicos imputa a possibilidades de deixar em suspensão modos cotidianos de ser/fazer/sentir/compreender e construir outras organizações de si e compreensões sobre o outro e sobre a relação eu-outro.

A relação do senso comum e o ensino de Sociologia é assinalada por Oliveira (2011) que pontua os desvios e o possível reducionismo da relação entre Sociologia e preparação para a cidadania, já expostos na LDB/96, se mantida esta tarefa como única e última. Para Oliveira (2011) a Sociologia deveria centrar-se na desnaturalização da realidade, na medida em que esta, não possui caráter essencialista. "Talvez, neste sentido, possamos afirmar que a pretensão da sociologia reside numa busca por um giro cognitivo, a ser experenciado pelo aluno da educação básica, este também 
compreendido a partir de uma teia de relações histórica e socialmente situadas" (OLIVEIRA, 2011, p. 32). Esse giro cognitivo está relacionado à promoção da possibilidade de "ver novamente o que já foi visto", de "explicar o que já foi explicado", ou seja, do educando construir outras compreensões sobre a realidade, tendo como base a sua própria visão, o senso comum. Destacamos aqui o termo "experenciado", pois denota que a desnaturalização ocorre pelo aluno na atribuição de sentido, isto é, o professor pode criar tempos-espaços de promoção da desnaturalização, mas este é um processo que embora relacionado às questões culturais e sociais, acontece como tarefa individual, na medida da desnaturalização da "visão do mundo".

A compreensão da desnaturalização como tarefa individual sendo que esta indica um processo de aquisição de conhecimento, ou seja, de expansão cognitiva, contém a concepção de indivíduo socializado, na estrita relação das influências socializadoras e a constituição da individualidade, que em diferentes perspectivas pode ser conceituado pela Sociologia do Conhecimento de Berger e Lukmann (2004) e pela Teoria Disposicional de Bourdieu (2003) ou de Lahire (2004). Nesse sentido, a desnaturalização que acontece no indivíduo para o indivíduo, precisa ser relativizada principalmente em três aspectos interdependentes: (1) que a desnaturalização como processo individual está na relação com a própria constituição de indivíduo socializado, ou seja, que a possibilidade da desnaturalização está entre a estrutura social-cultural e o percurso biográfico socializado; (2) que a desnaturalização acontece na relação entre a estrutura e dinâmica escolar e curricular e a atribuição de significação social e de sentido individual, aqui especificamente na disciplina de sociologia; e, (3) que a construção de conhecimento significa a expansão cognitiva e do horizonte biográfico. Expansão do conhecimento individual que sinaliza expansão da experiência na relação com o outro. Conhecimento expansivo ou em expansão, pois relacionado à dinâmica de desnaturalizar e, que expande a si e o outro na compreensão e na ação para si e para o outro. Dinâmica de desnaturalização que se reveste em possibilidade de suspensão.

Se as OCN (2006) centram seus objetivos no estranhamento, na desnaturalização e no desenvolvimento da imaginação sociológica, os PCNEM (1999) e as Orientações Educacionais Complementares aos Parâmetros Curriculares Nacionais ( $\mathrm{PCN}+$, 2002) enfocam na questão da criticidade e da cidadania. Contudo, principalmente, neste último documento, o desenvolvimento da conscientização, da crítica e da formação 
cidadã, compreendidos como processos integrados, ocorre pela percepção da relação do social com o individual, da relação entre a biografia e a história social.

As indicações do trabalho pedagógico com a realidade dos educandos, a vida dos educandos, as histórias de vida, as biografias, é realizada não somente como compreensão da relação entre condicionantes sociais e histórias individuais, o que permite conscientização e, por consequência a possibilidade da crítica, mas como fundamento da ação no social para a sua transformação e/ou ainda no exercício da cidadania. Compreender como os indivíduos atuam nas mudanças sociais e como é possível agir para transformar, como a política interfere no agir cotidiano dos indivíduos e grupos, como o poder permeia as relações sociais são objetivos da Sociologia no Ensino Médio, cuja indicação didático-metodológica pode ocorrer pela via de relatos orais e histórias de vida.

Diferentes orientações como os PCNEM (1999), PCN+ (2002) e OCN (2006) e o livro Sociologia (2010) são ao mesmo tempo complementares e díspares no que se refere ao ensino de Sociologia no Ensino Médio tanto em relação à formatação dos conteúdos quanto dos seus objetivos. O que os documentos asseguram é a autonomia do professor diante do exposto para que este articule os conteúdos curriculares com a realidade escolar e a especificidade dos alunos.

Contudo, ao expor quer seja sobre o desenvolvimento do estranhamento, da desnaturalização e da imaginação sociológica $(\mathrm{OCN})$, quer seja, da criticidade e cidadania pela conscientização de si (PCNEM, PCN+); ou ainda, compreender a vida cotidiana, ampliar a "visão de mundo" e o "horizonte de expectativas", nas relações interpessoais (PCNEM) o que se expõe como tarefa, como objetivo e como método é a relação entre História, estrutura social e trajetórias individuais, o que se realiza são indicações do trabalho com as biografias dos estudantes do Ensino Médio. Afinal ampliar a "visão de mundo" e os "horizontes de expectativas", necessita compreender a si mesmo, a sua história na perspectiva de um devir.

É nessa relação entre indivíduo e sociedade, na compreensão dos indivíduos enquanto produtos e produtores do meio social que a definição do olhar sociológico ou de imaginação sociológica de Mills (1975, p. 12) se encontra, pois "a imaginação sociológica nos permite compreender a história e a biografia e as relações entre ambas dentro da sociedade”. Para Berger (2011, p. 65) “a consciência sociológica constitui não 
só uma interessante novidade histórica que se pode estudar com proveito, como também uma ação bastante real para o indivíduo que procura ordenar e dar sentido aos fatos de sua própria vida".

Mills (1975) defende a concepção de que os homens modernos não necessitam de mais informações ou habilidades racionais para conseguirem dissipar a sensação de impotência e encurralamento diante das adversidades sociais e históricas, mas sim de uma "qualidade de espírito que lhes ajude a usar a informação e a desenvolver a razão, a fim de, perceber com lucidez o que está ocorrendo no mundo e o que pode estar acontecendo dentro deles mesmos" (MILLS, 1975, p. 11). A essa qualidade de espírito o autor denomina de imaginação sociológica, definida como a capacidade de compreensão da relação dos significados para a vida íntima e social da história e estrutura social. "A imaginação sociológica nos permite compreender a história e a biografia e as relações entre ambas, dentro da sociedade. Essa é a sua tarefa e a sua promessa" (MILLS, 1975. p. 11-12).

Para Berger (2011, p. 48) a sociologia tem como princípio o desenvolvimento da consciência sociológica compreendida como "a capacidade de olhar uma situação dos pontos de vista de sistemas interpretativos antagônicos. [...] a consciência sociológica seja inerentemente desmistificadora". Apesar de Berger (2011) centrar que o foco da sociologia são os processos de interação social e o modo como os sistemas sociais funcionam, o autor aponta que a compreensão das interações sociais serve para dar sentido aos fatos da própria vida, assim como a compreensão dos sistemas sociais necessita da compreensão/localização de si no tempo/espaço social. Assim, pode-se concluir que tanto para Mills (1975) como para Berger (2011) a relação entre os processos sociais e as biografias individuais é uma condição para a compreensão da sociedade e de si.

Tais reflexões levam a problematização dos conteúdos, metodologias, didáticas na medida em que a Sociologia enquanto disciplina curricular pode ser tanto fixada em teorias clássicas e contemporâneas, na definição de conceitos sem ser contextualizada e vinculada a realidade e as percepções dos jovens sobre suas vivências, como ser promotora de processos de desnaturalização e estranhamento pela relação entre biografias e condicionantes sociais, ou seja, como promotora de sentidos. Desse modo, é revelador o depoimento de Bourdieu no livro $O$ Sociólogo e o historiador 
(BOURDIEU; CHARTIER, 2012, p.16) quando expõem as escolhas entre "apresentar a sociologia como uma disciplina acadêmica, ou (...) exercer o efeito específico da sociologia, isto é, tento colocar meus ouvintes em situação de autoanálise".

A discussão que Bourdieu apresenta entre pôr a Sociologia em seus conteúdos conceituais e teóricos e produzir efeitos de reflexividade adentra a discussão do que ensinar, por que ensinar e como ensinar. Esta "situação de autoanálise" a que Bourdieu se refere se aproxima da compreensão de desenvolvimento da imaginação sociológica de Mills (1975) e da consciência sociológica de Berger (2011). Estas definições apontam para a concepção de que a tarefa da Sociologia é estabelecer relações entre os contextos sociais amplos e as biografias individuais, ou seja, é ver-se nesta relação.

Pela sociologia disposicional e contextual de Lahire $(2004,2006)$ ao abordar as questões da variabilidade intraindividual também se reflete sobre a relação entre o social e as trajetórias individuais. Mas o próprio Lahire $(2002,2004,2006)$ pontua em seus textos as diferenças nas concepções de socialização entre ele, Bourdieu e Berger e Luckmann, para citar alguns autores que compõem este trabalho. Contudo, ao tornarmos tais perspectivas teóricas centrais para refletirmos sobre o ensino de sociologia e, mais especificamente, sobre uma metodologia e um método, o que fazemos é por no ensino de ciências sociais/sociologia a centralidade da relação do social com o individual, pois como bem lembra Houle (2012, p. 329) "a vida em sociedade é o objeto primeiro e último da sociologia, e que só há sociedade e vida em sociedade a partir do momento em que isso faz sentido".

Em relação às teses da Sociologia do Conhecimento de Berger e Luckmann (2004) citaremos três críticas que Lahire (2004) realiza: $\left(1^{a}\right)$ a concepção da objetivação do mundo social; $\left(2^{\mathrm{a}}\right)$ a socialização como um processo de interiorização pela apreensão, e; $\left(3^{\mathrm{a}}\right)$ que os conteúdos da socialização são determinados pela distribuição social do conhecimento. A contraposição que Lahire $(2004,2006)$ realiza reside: $\left(1^{\circ}\right)$ o mundo social não se apresenta sob a forma de imposições sociais abstratas e separadas; $\left(2^{\circ}\right)$ a socialização pode ocorrer por treinamento ou por prática direta, como resultado de um efeito mais difuso da ordenação ou da organização de uma situação ou pela inculcação ideológico-simbólica de crenças difundidas por todo o tipo de instituições; e $\left(3^{\circ}\right)$ que há uma pluralidade de experiências socializadoras e de contextos relacionais 
em matéria cultural o que produz efeitos de socialização dissonantes e variações intraindividuais dos comportamentos.

Em relação a Bourdieu o que Lahire $(2002,2006)$ realiza é uma crítica, embasada em pesquisa empírica, principalmente, sobre a teoria do habitus e a teoria dos campos, ou seja, a teoria disposicionalista da ação e a interpretação da variação social. Mas esta crítica é realizada na consciência de ser um prolongamento da teoria de Bourdieu, ou seja, no reconhecimento de se constituir como uma base de orientação sociológica, nem desprezível, nem ideologizada, pois segundo Lahire (2004, p. 25) é em Bourdieu que se encontra o "maior esforço de explicitação em matéria de teoria disposicional da ação". Lahire (2006, p.18) ao realizar uma "reflexão sociológica sobre o mundo social em escala individual", pretende tal como Bourdieu romper com a dicotomia entre "a sociedade" e "o indivíduo", pois como afirma Bourdieu (2003, p. 33) “o corpo socializado (aquilo a que se chama o indivíduo ou a pessoa) não se opõe a sociedade: é uma das suas formas de existência" e Lahire (2006, p. 20) explica que é necessário "mostrar que as realidades individuais são sociais e que são socialmente produzidas".

Se o habitus na concepção de Bourdieu (2007) se inscreve como princípio mediador entre as práticas individuais e os contextos sociais de existência, a contestação que Lahire (2004) realiza é a de que a construção das disposições que constituem o habitus não pode ser restringida às condições de existência de classe ou a tendência da trajetória. Para Bourdieu (2007, p. 97) o habitus é compreendido como "principio unificador e gerador das práticas, ou seja, o habitus de classe, como forma incorporada da condição de classe e dos condicionamentos que ela impõe"; ou ainda, um "sistema de disposições socialmente constituídas que enquanto estruturas, estruturadas e estruturantes constituem o princípio gerador e unificador do conjunto das práticas e das ideologias características de um grupo de agentes" (BOURDIEU, 2007, p. 191). E a objeção que Lahire (2004) realiza é justamente a de "evidenciar a pluralidade das fórmulas geradoras das práticas incorporadas em cada indivíduo". Pluralidade por estarmos inseridos em uma sociedade extensa, complexa e diferenciada e pelo "fracasso" das socializações individuais, conceito que Lahire (2004, p. 325) utiliza de Berger e Luckmann (2004), o que impossibilita a configuração de quadros de disposições "perfeitamente coerentes e absolutamente harmônicos". 
Em relação ao ensino de Sociologia Lahire (2014) em texto intitulado Viver e interpretar o mundo social: para que serve o ensino de Sociologia?, realiza uma reflexão que dá fundamento e sentido para o ensino de Sociologia nas sociedades democráticas que visam a formação de cidadãos no exercício da vida coletiva. Lahire (2014) ao defender que a Sociologia estivesse incluída desde o ensino fundamental na escola, fala da necessidade do aprendizado de "hábitos intelectuais fundamentais" da Sociologia que se refere à observação e à objetivação do mundo social.

"Fazer ascender as realidades que permanecem invisíveis frente à experiência imediata [...] construir objetos jamais observados, vistos ou "vividos" como tais, e sem nenhuma visibilidade de um ponto de vista comum" (LAHIRE, 2014, p. 58); “desvelar coisas escondidas e por vezes recalcadas (BOURDIEU, 2003, p.24); a desmistificação do social por observar uma situação através dos pontos de vista de sistemas interpretativos antagônicos (BERGER, 2011); "perceber com lucidez o que está ocorrendo no mundo e o que pode estar acontecendo dentro deles mesmos" (MILLS, 1975, p. 11). Sentidos, objetivos e efeitos da Sociologia enquanto ciência do social que se aproximam enquanto proposta mas que apresentam especificidades na própria compreensão da relação indivíduo-sociedade. Mas, que significam e fundam a importância do ensino de Sociologia/Ciências Sociais na escola básica ainda mais se relacionadas as diretrizes e orientações curriculares para a educação básica que, de forma ampla, objetivam a construção da autonomia, da criticidade e de uma educação plena.

Lahire (2014) ainda realiza uma classificação em relação à utilidade e à natureza da Sociologia, contudo, na perspectiva da Pesquisa (Auto)biográfica em Educação ${ }^{4}$ a compreensão de si, a aprendizagem e ação no social (ação política) não se desvinculam. Pois como escrevem Pineau e LeGrand (2012, p.145) fazer história de vida "é tentar extrair mais-valia social de sua própria vida. Trata-se, portanto, de uma prática que

\footnotetext{
${ }^{4}$ No Campo da Pesquisa (Auto)biográfica em Educação há uma diferenciação terminológica e conceitual entre biografia, autobiografia, relatos de vida e histórias de vida que se faz necessário elucidar, na medida em que, é este campo de pesquisa e formação que fundamenta a pesquisa aqui relatada. Assim, conforme Souza (2006), embasado em Pineau (1999) a biografia se refere a escrita da vida do outro; a autobiografia como a escrita de si, da própria vida; os relatos de vida que se debruçam sobre configurações de uma trajetória de vida; e, a História de vida concebida como uma denominação genérica em formação e investigação que congrega uma variabilidade de pesquisas e projetos envolvidos na construção de sentidos com base nas trajetórias individuais, que envolve segundo Pineau (2012) um processo de expressão da experiência.
} 
mobiliza grandes interesses públicos e que faz parte dos movimentos de reorganização social dos circuitos de produção e difusão dos saberes".

Os processos de biografização descritos por Delory-Momberger (2012a) na relação com as pesquisas biográficas em formação têm uma dimensão definida entre biografia e aprendizagem. Um dos pressupostos da biografização é o de que os saberes subjetivos e não formalizados influenciam no modo como as pessoas investem e transitam nos espaços de aprendizagens formais e que tornar-se cônscio destes saberes torna possível ressignificar sentidos e projetos de vida em formação (DELORYMOMBERGER, 2006). Os processos de biografização ${ }^{5}$ implicam no estabelecimento da relação entre o social e o individual, a fim de questionar/problematizar as construções biográficas mediante os condicionantes sociais, políticos, históricos, culturais.

Delory-Momberger (2012a, p. 525) esclarece que a atividade biográfica "reporta, em primeiro lugar, a uma atividade mental e comportamental, a uma forma de compreensão e de estruturação da experiência e da ação, exercendo-se de forma constante na relação do homem com sua vivência e com o mundo que o rodeia". Estas interrogações nos processos de biografização entre a construção e o saber sobre as histórias de vida e os contextos e processos de socialização nos interessa especificamente na propositiva de fomentar estranhamentos e desnaturalizações através de relatos autobiográficos, além da não intencionalidade de encontrar normas, normalidades e regularidades. $\mathrm{O}$ que se pretende é visualizar a possibilidade dos efeitos dos relatos autobiográficos construídos dentro do espaço/tempo da sala de aula por jovens adolescentes a fim de produzir estranhamentos e desnaturalizações que levem a aprendizagens, mas também a estados de suspensão do saber.

É importante elucidar também o próprio conceito de formação e de experiência formadora, no sentido do uso de relatos autobiográficos como dispositivos de formação.

\footnotetext{
${ }^{5}$ É necessário especificar os conceitos de fato biográfico e de biografização, que decorre das leituras de Delory-Momberger (2009). O fato biográfico se inscreve em nós, em nosso interior, em nossas percepções do vivido, ainda não, talvez, compreendido e significado, ainda não narrado e explicitado em uma sequência que proporciona encadeamento e sentido. $\mathrm{O}$ fato biográfico se refere aos silêncios do vivido que constituem as memórias. $\mathrm{O}$ fato biográfico se refere aquela imagem do eu experenciado, mas ainda não compreendido entre a singularidade e a socialização, entre o eu e aquilo que me aconteceu. A biografização necessita e precede o fato biográfico que "consiste na ação de escrever (grafar) a narrativa de sua própria história de vida (autobiografia) e ou a história de vida de outrem (biografia)" (PASSEGGI, 2011, p.15).
} 
Neste ínterim, encontramos em Josso (2010) no livro Experiências de vida e formação, quando a autora expõe a sua compreensão sobre a "formação como atividade de um indivíduo em relação consigo mesmo, com o seu meio humano e natural no seu percurso de vida" (JOSSO, 2010, p. 245). O conceito de experiência formadora é compreendido como "uma articulação conscientemente elaborada entre atividade, sensibilidade, afetividade e ideação. Articulação que se objetiva numa representação e numa competência" (JOSSO, 2010, p. 47-48). Este conceito caminha na perspectiva de Dewey (2010) em que vida, experiência e aprendizagem são processos inseparáveis e mutuamente referentes. Para Dewey, a experiência educativa tem como função e efeito a percepção de relações e continuidades não percebidas anteriormente e, assim, pela compreensão de outros sentidos, há possibilidades de construção ou geração de novas perspectivas futuras.

Relatar-se, autobiografar-se pode ser compreendido como uma experiência e como um meio de dar materialidade ao saber da experiência. Trabalhar com relatos autobiográficos em sala de aula pode servir como uma abertura ao processo de questionar, em que o próprio ato de relatar-se produz estranhamentos. O relatar-se como ato pedagógico pode fomentar a ampliação da visão de mundo e horizontes de expectativas, e por isso tornar-se uma experiência formadora, pois relacionado a suspensões de saberes e ressignificações.

Passeggi (2011) ao abordar sobre as narrativas (auto)biográficas como prática de formação do adulto, expõe sobre a potencialidade dos relatos autobiográficos e a sua consequente contribuição para o protagonismo individual ao expor que a prática da biografização tem como efeito a "reversibilidade sobre o pensamento de quem narra, transformando representações de si mesmo e da vida. Essa ação regressiva e progressiva é que permite falar de "si mesmo" como um "eu refletido", reinventado pela ação de linguagem" (PASSEGGI, 2011, p.26).

Bourdieu (1997, p.704-705) em texto intitulado Compreender ao falar sobre as questões da entrevista sociológica menciona "sentir uma espécie de alívio, até de realização, tudo neles lembra a felicidade de expressão"; "auto-análise provocada e acompanhada"; "enunciar, às vezes, com uma extraordinária intensidade expressiva, experiências e reflexões há muito reservadas ou reprimidas" para expor os efeitos que a narração de si pode provocar. 
É a reflexividade autobiográfica apontada por Passeggi (2011) que justifica e fundamenta o diálogo entre a abordagem (auto)biográfica como dispositivo de formação e a Sociologia no ensino médio, na perspectiva da construção de espaços de possibilidade de estranhamentos, desnaturalizações e do desenvolvimento da imaginação sociológica e ainda na formação da consciência de si e do outro, da crítica e da autonomia.

Lahire (2006, p. 336) aponta que a parcela de "liberdade" que temos na compreensão de que nossos comportamentos decorrem da interação entre disposições internas e contextos externos sendo assim permeados pelas influências "consiste em modificar as influências internas e externas que agem em nós e sobre nós”. Embasado em sua pesquisa Lahire (2006, pg. 336) escreve que "o auto-conhecimento (de suas propensões) pode levar 1) a um autocontrole para conter a força da disposição ou 2) a arranjos contextuais que deem conta dessa disposição para tentar limitar seus efeitos negativos".

Auto-conhecimento se o relato de si for sentido como uma experiência, se houver implicação no ato de narrar-se, intenção de compreender-se, se for atribuído sentido ao que é narrado e ao ato de narrar-se, pode-se pensar que a construção de espaços de possibilidade da narratividade de si ruma a um devir, na própria elaboração da experiência ou biografização da experiência, no dizer de Delory-Momberger (2012b) traspassada pela postura de ignorar o que será narrado. $\mathrm{O}$ importante é reconhecer que os relatos produzem efeitos de si para si e que estes inseridos em um espaço escolar podem gerar estranhamentos, ser fontes de desnaturalizações, promover aberturas, suspensões, ressignificações e assim, construções e reconstruções da experiência.

\section{Apresentação e análise da aplicação de uma proposta de ensino de sociologia}

A escola pública em que foi aplicada a proposta localiza-se na região central do Rio Grande do Sul, na periferia da cidade. Em 2014, o complexo temático definido a partir da pesquisa socioantropológica foi "O meu valor, o teu valor, os nossos valores". O Projeto Político Pedagógico (2014) da escola apresenta a concepção de que os conhecimentos devem partir daquilo que o aluno adquiriu na sua história de vida e de 
acordo com a comunidade escolar. Destaca como tarefa a formação de cidadãos conscientes, responsáveis e que acreditem em suas potencialidades.

Foram trabalhadas com cinco turmas do primeiro ano do Ensino Médio, durante os períodos de aula de sociologia, com 81 jovens que, por critérios particulares 77 participaram ativamente da proposta. A atividade foi desenvolvida nos meses de outubro e novembro de 2014. O tema escolhido (Cultura) para a realização da proposta foi dado pela professora regente da disciplina para que a atividade acompanhasse o desenvolvimento da disciplina. Para o conteúdo de base foi utilizado o texto Cultura e alteridade de Simões e Giumbelli (2010). O tempo de inserção na escola foi acompanhado pela escrita de um Diário de Campo que apresenta reflexões ao pôr em prática uma proposta de ensino que se deseja pesquisar; e, da relação eu - outro.

A realização da proposta de ensino de Sociologia com a abordagem (auto)biográfica como dispositivo de formação teve como fio condutor as fases descritas por Josso (2010) sobre a abordagem biográfica como metodologia da pesquisaformação ${ }^{6}$. Para ela

a originalidade da metodologia de pesquisa-formação em histórias de vida diz respeito, em primeiro lugar, à nossa constante preocupação com que os autores de narrativas consigam produzir conhecimentos que tenham sentido para eles e que eles próprios se inscrevam num projeto de conhecimento que os institua como sujeitos (JOSSO, 2010, p. 33).

Para esclarecer o aporte metodológico desta pesquisa é necessário destacar que a relação entre conhecimento, sentido e construção de si, apontadas por Josso (2010); a reflexividade autobiográfica destacada por Passeggi (2011) que implica uma autonomia cognitiva e a conscientização de si em organizações dinâmicas de compreensão de si; e, a relação entre biografia e aprendizagem de Delory-Momberger $(2006,2011,2014)$ está na centralidade da contribuição epistemológica do campo da Pesquisa (Auto)biográfica em Educação, além da possibilidade da construção de uma proposta didática. A relação

\footnotetext{
${ }^{6}$ Descrição das fases: 1) fase de introdução à construção da narrativa da história de vida, em que o mediador expõem os seus caminhos intelectuais que originaram as questões teóricas sobre formação e a percepção sobre a abordagem biográfica; (2) fase de elaboração da narrativa, que pode ocorrer pela escolha de uma ou diversas temáticas que irá circunscrever a narrativa ou a reconstituição livre de um determinado percurso; (3) fase de compreensão e de interpretação das narrativas escritas; cuja interpretação e análise pode ser realizada na relação com referenciais teóricos sobre a temática que conduz as narrativas; e, (4) fase de balanço dos formadores e dos participantes.
} 
entre biografia e aprendizagem em Delory-Momberger (2006, 2011, 2014) pode ser identificada nos seguintes aspectos: (1) que os saberes subjetivos e não formalizados influenciam no modo como as pessoas investem e transitam nos espaços de aprendizagens formais e que tornar-se cônscio destes saberes, torna possível ressignificar sentidos e projetos de vida em formação (DELORY-MOMBERGER, 2006); (2) que a compreensão dos significados das experiências de formação e aprendizagem de jovens e adultos em suas construções biográficas individuais, nas suas relações com os outros e com o mundo social torna-se constituidor (DELORYMOMBERGER, 2011); e, (3) que a aprendizagem de saberes escolares estabelece uma relação de complementaridade e reciprocidade com as aprendizagens e saberes biográficos, permitindo revisitações de si e outras projeções, ou ainda, "biografar-se de outro modo" (DELORY-MOMBERGER, 2014, p.136). O estranhamento e a desnaturalização como princípios epistemológicos do ensino de sociologia que incide sobre si e o outro e que possibilita compreender e compreender-se de outro modo referese a possibilidade de "biografar-se de outro modo" para retomar Delory-Momberger (2014) e para substanciar a relação aqui defendida entre o campo da Pesquisa (Auto)Biográfica em educação como dispositivo de formação e o ensino de sociologia na educação básica.

Para a relação entre sociologia e biografias individuais construiu-se uma metodologia de intervenção nas aulas de Sociologia no ensino médio, que ocorreu nas seguintes etapas: (1) Sensibilização do grupo em relação às escritas de si, com exposição do mediador sobre os objetivos da proposta; (2) Elaboração de narrativas escritas sobre o enfoque de um determinado tema da sociologia (cultura) na relação com as experiências de vida; (3) Fase de interpretação das narrativas escritas. Leitura e interpretação em pequenos grupos de três pessoas; (4) Desenvolvimento do tema; (5) Releitura dos primeiros relatos escritos e reinterpretação dos mesmos na relação com o tema trabalhado em aula; (6) Re-escrita dos relatos, das possíveis novas interpretações, dos aprendizados; (7) Fase de balanço, em grande grupo. Uma conversa cuja finalidade assenta-se em conhecer e compreender as percepções sobre o experenciado.

A análise dos relatos, decorrentes da proposta, foi realizada com base na Análise Textual Discursiva (ATD) de Moraes (2003) e Moraes e Galiazzi (2007) cujo “corpus” de análise é constituído basicamente de produções textuais. A ATD se caracteriza por 
um ciclo de análise em três focos: (1) desconstrução e unitarização; (2) estabelecimento de relações, o processo de categorização; e, (3) construção de um metatexto (descrição, interpretação, compreensões e teorizações). A categorização realizada através da ATD permite a compreensão de que os textos embora divididos em unidades e categorias de análise estas podem se interpenetrar nos discursos textuais.

A ATD incidiu sobre os relatos produzidos pelos jovens participantes da proposta. Contudo a principal contribuição epistemológica da ATD centra-se na relação que estabelece entre categorização e teorização, ao apresentar-se nas modalidades de $a$ priori e emergentes (MORAES; GALIAZZI, 2007), o que permitiu não somente uma interpretação em base das teorias deste trabalho, mas um exercício de teorização sobre os dados e categorias levando a ampliação e a construção de outras compreensões.

$\mathrm{Na}$ primeira etapa de desconstrução e unitarização dos relatos foram identificadas duas unidades de base construídas na concepção de educação de Dewey (2010): (1) Educação como construção e reconstrução da experiência; e (2) Atividade de não significação. No processo de categorização e estabelecimento de relações os textos foram interpretados conforme categorias amplas, intermediárias e peculiares ${ }^{7}$, conforme quadro 01.

Quadro 1: categorias de análise

\begin{tabular}{|c|c|c|}
\hline \multicolumn{3}{|c|}{ Unidades de base } \\
\hline \multicolumn{3}{|c|}{$\begin{array}{c}\text { Educação como construção e reconstrução da experiência } \\
\text { Atividade de não significação. }\end{array}$} \\
\hline $\begin{array}{l}\text { Categorias amplas } \\
\text { (a priori) }\end{array}$ & $\begin{array}{l}\text { Categorias intermediárias } \\
\text { (a priori/emergentes) }\end{array}$ & $\begin{array}{l}\text { Categorias peculiares } \\
\text { (categorias emergentes) }\end{array}$ \\
\hline \multirow[t]{3}{*}{ Estranhamento } & $\begin{array}{l}\text { Estranhamento de si, } \\
\text { Estranhamento do outro }\end{array}$ & $\begin{array}{l}\text { Pela diferença; } \\
\text { Pela igualdade; } \\
\text { Pela igualdade da diferença }\end{array}$ \\
\hline & Respeito/preconceito & \\
\hline & $\begin{array}{l}\text { Conhecimento } \\
\text { Reconhecimento }\end{array}$ & $\begin{array}{l}\text { Influência familiar } \\
\text { Disposição para a aprendizagem } \\
\text { Não disposição para a aprendizagem }\end{array}$ \\
\hline
\end{tabular}

\footnotetext{
7 Segundo Moraes (2003), na fase de categorização podem ser identificados diferentes níveis de categorias os quais o autor exemplifica em iniciais, intermediárias e finais. Preferimos, no entanto, denominar os níveis de categorização em categorias amplas, intermediárias e peculiares pela recursividade na análise que elas apresentam. As categorias também podem ser classificadas em a priori tendo por base os objetivos e as teorias do projeto e, em emergentes que são categorias construídas a partir da leitura do corpus de pesquisa.
} 


\begin{tabular}{|c|c|}
\hline Individualização & $\begin{array}{l}\text { Descrição pessoal } \\
\text { Percepção de que a cultura não } \\
\text { influencia ou que não segue uma cultura } \\
\text { Percepção de que eu escolho ou crio a } \\
\text { cultura que quero }\end{array}$ \\
\hline & $\begin{array}{l}\text { Literalidade } \\
\text { Substancialidade }\end{array}$ \\
\hline
\end{tabular}

Fonte: elaboração do autor (2015).

A análise, o estabelecimento de relações entre as categorias e a interpretação gerou compreensões que versam sobre: (1) A desnaturalização como condição da construção e reconstrução da experiência, identificadas pela literalidade das explicações, dos conceitos ou pela substancialidade; (2) Estranhamento de si pela reflexividade na escrita e estranhamento do outro pela leitura dos relatos de outros e pela dinâmica. Estranheza ao perceber a diferença, a igualdade, e a igualdade da possibilidade em ser diferente; (3) Importância de um tema que conduza a reflexão; (4) Reflexões sobre o preconceito como decorrência do estranhamento e da desnaturalização; (5) A consciência de si como um indivíduo que se constitui em meio às influências (conhecimento/reconhecimento) revelou-se como um elemento de disposição para a aprendizagem, para a reconstrução da experiência. A percepção da influência familiar corrobora esta interpretação; e, (6) Percepção de autoconstrução de si individualizada e individualizante resultou em uma não disposição/abertura para outras reflexões e/ou possibilidades de outras percepções de si e do outro. Assim, refletimos que:

(1) O conceito de experiência educativa em Dewey (2010), de forma geral, envolve reflexão, dotada de significação, em que se percebem relações e continuidades antes não percebidas, em que a aquisição de novos conhecimentos é um resultado natural. Este conceito de experiência educativa é amplo e pode abranger a desnaturalização que significa procurar compreender as interpretações e explicações sobre as relações sociais de modo não naturalizado, ou seja, compreender a historicidade dos fenômenos sociais e compreendê-los como decorrentes das razões humanas, das ações humanas. É possível fazer a relação entre desnaturalização e experiência educativa, colocando a desnaturalização como um elemento da experiência educativa. A análise dos relatos possibilitou perceber, identificar a desnaturalização nos relatos que revelam uma experiência educativa de duas formas: (a) pela literalidade das 
explicações, dos conceitos e (b) pela substancialidade. Pela literalidade, que comporia a expressão dos conceitos, a experiência aqui analisada constou em mais da metade dos relatos em que se apresenta uma construção e reconstrução da experiência, já pela substancialidade, em que aparece não a definição dos conceitos, mas a ideia do que o caracteriza e a abordagem temática refletidos em experiências/possibilidades práticas há uma totalidade, pois perceber relações e continuidades antes não percebidas envolve pôr em questão (estranhar) os conhecimentos prévios e adquirir novas compreensões (desnaturalizar).

(2) Estranhamento de si pela reflexividade na escrita e estranhamento do outro pela leitura dos relatos de outros e pela dinâmica. O estranhamento de si e/ou do outro aparecem mediados pelas dinâmicas de reflexão. A escrita refletida de si comporta, necessita do estranhamento, pois é necessário ver-se, distanciar-se de si mesmo. Josso (2010) pontua que o distanciamento da narrativa de si somente funciona como uma mudança na auto-percepção quando há uma implicação pessoal. Assim, os relatos que apresentaram uma experiência educativa (uma construção e reconstrução da experiência) comportam o estranhamento de si. Porém, o estranhamento de si, nem sempre implicou um estranhamento do outro, pois o mesmo pode ser visto em relações naturalizadas e inquestionadas (questiono a mim, mas não a ação/posição do outro sobre mim). Entrar em contato com o relato de outros (heterobiografia) e vivenciar uma dinâmica que revela e confronta o eu-outro instigou ao estranhamento desse outro. Contudo, o estranhamento do outro e de si ocorreu em três perspectivas: (1) pela diferença, de estranhar o familiar; (2) pela igualdade, por perceber o compartilhamento de elementos culturais no diferente (relação exótico-familiar), e; (3) pela igualdade da diferença, em perceber que a característica e possibilidade da diferença os tornam iguais em humanidade. Nesse sentido, Josso (2010, p. 224) se questiona "se a tomada de uma consciência da estranheza de si pela mediação-confrontação com a estranheza do outro não é um dos desafios mais urgentes em educação", desafio que poderia servir como expressão desta proposta de ensino.

(3) Importância de um tema que conduza a reflexão. Relatos caracterizados mais por uma descrição de si, compreendida como uma definição pessoal (eu sou...) com ausências de uma reflexão sobre a constituição de si e ausências de relação com o tema proposto, não permitiu o desenvolvimento de transformações na percepção de si, o que 
corrobora a importância de um tema gerador. Este aspecto do tema que conduz a reflexão e a escrita de si vai ao encontro da segunda fase descrita por Josso (2010) sobre a abordagem biográfica como metodologia da pesquisa-formação, que compreende que a elaboração da narrativa pode ocorrer pela escolha de uma ou diversas temáticas para circunscrever a narrativa ou a reconstituição livre de um determinado percurso de formação, ou seja, em uma determinada perspectiva. Bertaux (2010, p.67) usa a expressão intenção de conhecimento que se refere à temática exposta pelo pesquisador em que o sujeito filtra, seleciona as suas experiências que serão narradas na perspectiva da narrativa de vida na finalidade da pesquisa etnossociológica o que difere de uma autobiografia. Como a intenção da proposta aqui realizada era que houvesse uma aprendizagem pela reconstrução da experiência a relação da narração autorreferencial com uma temática tornou-se sua condição. Esta afirmação não exclui, porém, a possibilidade de que relatos autorreferenciais livres possam gerar estranhamentos, sofrer processos de desnaturalização, mas isto implicaria outras mediações no processo de retorno a própria narrativa.

(4) As reflexões sobre a questão do preconceito e do respeito que se configuraram como categorias emergentes nos relatos, decorreram do processo de desnaturalização ao se compreender a dinâmica cultural e os conceitos de cultura e culturas, problematizando os aspectos de igualdade e diversidade humana. Assim como, das experiências de estranhamento citadas acima. O estranhamento de si e do outro implica a reflexão sobre a relação eu-outro, é ver-se na relação, nos modos de percepção e condução das relações. A releitura dos escritos de si, mediados por outras vivências, reflexões e compreensões permitiu conscientização e possibilidade no devir do estabelecimento de diferentes relações com o outro e consigo mesmo. Aqui poder-se-ia fazer relações com o conceito de emancipação que Pineau (2012, p.109) aborda ao tratar sobre os motivos e objetivos de querer fazer da vida uma história. A emancipação relaciona-se "com a libertação relativa operada pela tomada de consciência crítica e reflexiva dos determinantes existenciais por meio de sua expressão", cuja autoexpressão configura-se como um elemento necessário. (Re)apropriação, (auto)consciência e (auto)emancipação elementos que podem configurar a prática de histórias de vida (PINEAU, 2012) aqui fizeram sentido no desenvolvimento de toda a proposta que 
incluía escrita e leitura de si, do outro, mediação de novos conhecimentos e releitura e reescrita de si.

(5) Para Dewey (2010) é a intenção, o propósito de quem vai aprender que decide sobre o que será aprendido. Se aprendizagem é vida, a significação e a mobilização pelo sujeito aprendente é condição necessária. A intenção e a mobilização de conhecer são produzidas na medida em que o novo tenha alguma relação e faça algum sentido com o estabelecido. Dessa forma, ter uma consciência de si como um indivíduo que se constitui em meio as influências culturais-sociais (conhecimento/reconhecimento), em que a família tem papel preponderante na constituição do eu, revelou-se como um elemento de disposição para a aprendizagem, para a reconstrução da experiência. Houve, em menor intensidade, relatos que pela substancialidade compreendiam o conceito de cultura e indivíduos que se compreendiam como expressão dos condicionantes culturais, mas que não atribuíram significação a atividade desenvolvida. Uma interpretação possível é a fixação no já conhecido e a não motivação ou intenção de aprender que pode decorrer, dentre outras características, da vontade de refutar a desestabilização que o novo produz ao estabelecido. Pois, reafirmando, se aprendizagem é vida e a assimilação ativa de algum conhecimento associa-se a própria vida, a reconstrução da experiência ruma a reconstruções de si. Como afirma Delory-Momberger (2009, p.118) "no existe aprendizaje sino em la singularidad de una biografia".

(6) Bruner (2014) afirma que o modo e como contamos as narrativas a nós mesmos, que criam e recriam a nossa individualidade, é concernente a cultura em que vivemos. Assim, o eu deriva do nosso contar. Na perspectiva de Lahire $(2004,2006)$ o indivíduo, a individualidade não é algo que se registra, mas que se conquista e se constrói e que a coerência e a uniformidade idenditária é expressa e garantida na narração do eu, que tem sua justificativa no social, embora haja uma variabilidade, pluralidade de constituição das disposições do eu. Dessa forma, o modo como nos narramos, reafirmando Bruner (2014), e também como nos vemos e como queremos que os outros nos vejam tem fundamento no social e no cultural. Na concepção de Bauman (2008) a narração das histórias de vida, as histórias contadas não são as histórias vividas, mas são "estreitamente interconectadas e interdependentes", pois os indivíduos constroem e narram sua existência dentro de condições que modelam a vida 
e a narrativa. E assim, na sociedade moderna em que a tendência é a da individualização em que há ausências no processo de reconhecimento, de articulação entre os fatores sociais mais amplos e as biografias individuais tais características podem ser percebidas nas narrativas de vida. Bruner (2014) nos instiga ainda ao afirmar que as histórias que construímos ao nos definir hão instalado nelas elementos de enfrentamento das situações que vivenciamos. Dessa forma, encontramos possibilidade de compreensão dos relatos marcados por uma percepção de autoconstrução de si na ausência de uma reflexão sobre as possíveis influências sociais-culturais identificadas nos dizeres de que "eu crio...", “eu escolho...", “eu não sofro influência...", "ninguém me influencia...", cuja percepção e narração de si é atinente ao aspecto da individualização social. Também se reflete pela tentativa de autonomia e empoderamento de si característico da adolescência, o que leva a entender o relato de si na confluência entre características existenciais e condicionantes sociais-culturais. O conceito de individualização na teoria da modernização reflexiva é problematizado por Beck (1997) no sentido de um novo modo de condução e disposição da vida, em que desincorporação e reincorporação de modos de vida, tornam-se processos dinâmicos e sociais. A substituição de uma "biografia padronizada" por uma "biografia escolhida", no dizer de Beck (1997, p. 26) não se refere há uma livre escolha, mas há uma compulsão pela auto-gestão de si, pela auto-responsabilização e admissão dos riscos pessoais. Delory-Momberger (2012b, p. 56) expõe sobre a individualização do social através de individualidades singulares e concorda com Axel Honneth (2006) que "o individualismo normativo se converteu em ideologia da autorrealização”. Assim, Delory-Momberger (2012b) aborda tanto a questão do individualismo reflexivo que se refere ao retorno que o indivíduo faz a si mesmo e da auto-conscientização sobre a sua ação no social como o individualismo normativo que gera escassez de reflexividade e enfraquecimento do processo de construção de si. Na relação com os relatos e com a dinâmica realizada a compreensão é a de que a percepção de uma construção de si individualizada e individualizante afetou a própria intenção de aprender, ou ainda, a disposição para refletir sobre outras possibilidades de compreensão de si e do outro.

\section{Considerações finais}


A experiência de pesquisa aqui apresentada permite formular considerações que podem colaborar nas compreensões dos sentidos do ensino de sociologia e a potencialidade das escritas de si como dispositivo de formação no âmbito escolar. Isto porque as compreensões rumam para a corroboração da tese de que a utilização de dispositivos de auto e heterobiografia nas aulas de Sociologia/Ciências Sociais fomentam estranhamentos de si e do outro e a desnaturalização, podendo colaborar com a quebra de preconceitos. Embora no mesmo espaço formativo, outra relação eu-outro é vivenciada quando se atravessam elementos constituidores de si e do outro, histórias de vida antes não reveladas, antes não dadas a conhecer. A sociologia/ciências sociais ao desnaturalizar esses elementos constituidores do ser social, que é ao mesmo tempo individual, ao fazer compreender a historicidade, a igualdade e a diversidade humana através dos seus conceitos-temas-teorias, gera reflexões sobre si e sobre o outro, suspensões de saberes, novas compreensões e possibilidades do estabelecimento de outras relações.

As análises dos relatos indicaram: (1) A desnaturalização como condição da construção e reconstrução da experiência, identificadas pela literalidade das explicações, dos conceitos ou pela substancialidade; (2) Estranhamento de si pela reflexividade na escrita e estranhamento do outro pela leitura dos relatos de outros e pela dinâmica. Estranheza ao perceber a diferença, a igualdade, e a igualdade da possibilidade em ser diferente; (3) Importância de um tema que conduza a reflexão; (4) Reflexões sobre o preconceito como decorrência do estranhamento e da desnaturalização; (5) A consciência de si como um indivíduo que se constitui em meio às influências (conhecimento/reconhecimento) revelou-se como um elemento de disposição para a aprendizagem, para a reconstrução da experiência. A percepção da influência familiar corrobora esta interpretação; e, (6) Percepção de autoconstrução de si individualizada e individualizante resultou em uma não disposição/abertura para outras reflexões e/ou possibilidades de outras percepções de si e do outro.

O discurso, o objetivo de trabalhar ou partir da realidade dos educandos não é concernente especificamente a Sociologia/Ciências Sociais, ao contrário é difundido em teorias, diretrizes, orientações sobre a ampla esfera da educação escolar. Como projeto de educação nacional, as concepções de pleno desenvolvimento do educando (LDB, 1996) ou de desenvolvimento na sua plenitude (DCN, 2013) mantêm-se muito mais 
como uma possibilidade, uma promessa, um porvir do que como um cenário, uma base de ação cotidiana. Quando observamos as recontextualizações de diversos textos de orientação educacional construídos em diferentes instâncias de gestão educacional e escolar, quando observamos cotidianamente, as obliquosidades entre discursos e estruturas, entre interesses e práticas há uma inversão em que o desenvolvimento integral e pleno é subsumido, na prática, a inserção no mercado de trabalho e ao acesso aos níveis mais elevados do ensino ao término da educação básica, conforme a capacidade de cada um (LDB, 1996). A substituição no PNE (2014) de "expectativas de aprendizagem" por "direitos e objetivos de aprendizagens e desenvolvimento" relacionado a construção de uma base nacional curricular comum tenta atribuir o caráter de uma educação existente, presente, que se realiza e não apenas de uma probabilidade.

É redundante, mas necessário afirmar que uma educação plena concerne a uma educação de si, em que o si significa o eu refletido. Apesar de não nos alongarmos aqui nesta discussão, mas certamente não deixarmos para as calendas gregas, demarcamos que as Ciências Sociais, a Sociologia, pela sua própria especificidade enquanto ciência do social, enquanto compreensão do contexto presente, na relação entre indivíduo e sociedade tem importância indiscutível nessa tarefa educativa.

O conhecimento sociológico tem na relação sociedade-indivíduo a sua centralidade. Perceber e considerar a auto-observação e auto-reflexão como meio de estranhar para então questionar, avaliar e compreender as estruturas, os processos, os condicionantes sociais, para entender conceitos e temas, pode ser um procedimento significante, na medida em que faz o jovem compreender na sua própria trajetória a relação sociedade-indivíduo. Faz o jovem colocar-se em suspensão de saberes para outras reorganizações. Entre os dizeres de que é difícil pensar sobre si mesmo e a resistência a escrita de si, entre o estranhamento e a familiaridade em escrever-se, entre o revelado e o silenciado, a proposta aqui apresentada configura-se como uma possibilidade que visa a contribuir na compreensão do potencial das narrativas autorreferenciais nas aulas de Sociologia/Ciências Sociais, no potencial do ensino de Ciências Sociais/Sociologia para a formação humana.

\section{Referências}


BAUMAN, Z. A sociedade individualizada: vidas contadas e histórias vividas. Rio de Janeiro: Jorge Zahar, 2008.

BECK, U. A reinvenção da política: rumo a uma teoria da modernização reflexiva. In: BECK, U. GIDDENS, A. LASCH, S. Modernização reflexiva: política, tradição e estética na ordem social moderna. São Paulo: Editora Estadual Paulista, 1997, p. 11-72.

BERGER, P. Perspectivas Sociológicas: uma visão humanística. $31^{\mathrm{a}}$ ed. Petrópolis: Vozes, 2011.

BERGER, P. LUCKMANN, T. A construção social da realidade. Petrópolis: Vozes, 2004.

BERTAUX, D. Narrativas de vida: a pesquisa e seus métodos. Natal: EDUFRN, 2010.

BOURDIEU, P. A distinção: a crítica social do julgamento. Porto Alegre: Zouk, 2007.

Compreender. In: BOURDIEU, P. A Miséria do Mundo. Petrópolis, RJ: Vozes, 1997. p. $693-732$.

Questões de Sociologia. Lisboa: Fim de Século, 2003.

BOURDIEU, P.; CHARTIER, R. O sociólogo e o historiador. Belo Horizonte: Autêntica, 2012.

BRASIL. Ministério da Educação. Diretrizes Curriculares Nacionais para a Educação Básica - DCN. Brasília, 2013. Disponível em: $<$ http://portal.mec.gov.br/index.php?option $=$ com_docman\&view $=$ download\&alias $=155$ 48-d-c-n-educacao-basica-nova-pdf\&Itemid=30192 >. Acesso em: 16 abr. 2014.

BRASIL. Ministério da Educação. Lei de Diretrizes e Bases da Educação Nacional LDB. Brasília, $1996 . \quad$ Disponível em: $<$ http://www.planalto.gov.br/ccivil_03/Leis/L9394.htm>. Acesso em: 18 mar. 2012.

BRASIL. Ministério da Educação. Orientações Curriculares Nacionais para o Ensino Médio - OCN. v. 3Brasília, 2006. Disponível em: $<$ http://portal.mec.gov.br/seb/arquivos/pdf/book_volume_03_internet.pdf $>$. Acesso em: 16 ago. 2012.

BRASIL. Ministério da Educação. Orientações Educacionais Complementares aos Parâmetros Curriculares Nacionais: Ciências Humanas e suas Tecnologias.Brasília, 2002. Disponível em: $<$ http://portal.mec.gov.br/seb/arquivos/pdf/CienciasHumanas.pdf $>$. Acesso em: 16 ago. 2012. 
BRASIL. Ministério da Educação. Parâmetros Curriculares Nacionais para o

Ensino Médio. parte 4Brasília, 1999. Disponível em: $<$ http://portal.mec.gov.br/seb/arquivos/pdf/cienciah.pdf>. Acesso em: 16 ago. 2012.

BRASIL. Ministério da Educação. Plano Nacional de Educação - PNE. Brasília, 2014.

Disponível

em:

$<$ http://www.observatoriodopne.org.br/uploads/reference/file/439/documento-

referencia.pdf $>$. Acesso em: 20 abr. 2015.

BRASIL. Ministério da Educação. Sociologia: ensino médio. Coleção Explorando o Ensino; v. 15. (Coordenação Amaury César Moraes). Brasília, 2010. Disponível em: < http://portal.mec.gov.br/index.php?option $=$ com_docman\&view $=$ download\&alias $=7843$ 2011-sociologia-capa-pdf\&category_slug=abril-2011-pdf\&Itemid=30192>. Acesso em: 04 jul. 2014.

BRUNER, J. Fabricando histórias: direito, literatura e vida. São Paulo: Letra e Voz, 2014.

CARVALHO FILHO, J. L. de. O ensino de sociologia como problema epistemológico e sociológico. Educação e Realidade. v. 39, n. 1. jan.mar. 2014. Disponível em: $<$ http://www.scielo.br/scielo.php?pid=S2175-62362014000100005\&script=sci_arttext $>$. Acesso em: 27 abr. 2014. p. 59-80.

DELORY-MOMBERGER, C. Abordagens metodológicas na pesquisa biográfica. Revista Brasileira de Educação.v. 17, n. 51, set-dez 2012a. Disponível em: $<$ http://www.scielo.br/pdf/rbedu/v17n51/02.pdf >. Acesso em: 20 mar. 2014.

A condição biográfica: ensaios sobre narrativa de si na modernidade avançada. Natal: EDUFRN, 2012b.

Biografia y educacion: figuras del individuo-proyecto. Editorial de La Facultad de Filosofia y Letras da Universidad de Buenos Aires, 2009.

Biografia e educação: Figuras do indivíduo-projeto. Natal: EDUFRN, 2014.

. Formação e socialização: os ateliês biográficos de projeto. Educação e Pesquisa. v. 32 , n. 2, maio/ago. 2006. Disponível em: $<$ http://www.revistas.usp.br/ep/article/view/28015/29807>. Acesso em: 20 jul. 2013. p. 359-371.

DEWEY, J. Textos selecionados. In: WESTBROOK, R. B.; TEIXEIRA, A.; ROMÃO, J. E.; RODRIGUES, V. L. (org.). John Dewey. Recife: Massangana, 2010. Disponível em: <http://www.dominiopublico.gov.br/download/texto/me4677.pdf $>$. Acesso em: 12 abr. 2015 . 
GEERTZ, C. O senso comum como um sistema cultural. In: GEERTZ, C. O saber local: novos ensaios em antropologia interpretativa. 12 ${ }^{\mathrm{a}}$ ed. Petrópolis, RJ: Vozes, 2012. p. 77-97.

GRAMSCI, A. Apontamentos para uma introdução e um encaminhamento ao estudo da filosofia e da História da cultura. In. Cadernos do Cárcere. Volume 1. $3^{\mathrm{a}}$ ed. Rio de Janeiro: Civilização Brasileira, 2004.

HOULE, G. A sociologia como ciência da vida: a abordagem biográfica. In: POUPART, J. et al. (org.). A pesquisa qualitativa: enfoques epistemológicos e metodológicos. Petrópolis, RJ: Vozes, 2012. p. 317-336.

JOSSO, M-C. Experiências de vida e formação. Natal: EDUFRN, 2010.

LAHIRE, B. A cultura dos indivíduos. Porto Alegre: Artmed, 2006.

Reprodução ou prolongamentos críticos? Educação \& Sociedade, ano XXIII, no 78, abril 2002. Disponível em: <http://www.scielo.br/pdf/es/v23n78/a04v2378.pdf>. Acesso em: 15 jan. 2015.

Artmed, 2004.

Retratos Sociológicos: disposições e variações individuais. Porto Alegre:

Viver e interpretar o mundo social: para que serve o ensino da Sociologia?

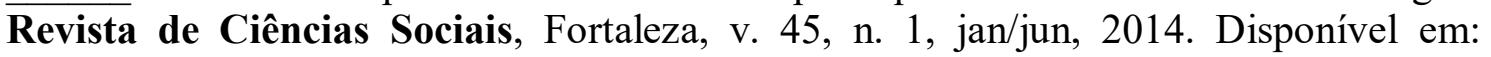
$<$ http://www.rcs.ufc.br/edicoes/v45n1/rcs_v45n1a2.pdf $>$. Acesso em: 05 dez. 2014.

MILLS, C. W. A imaginação sociológica. $4^{\mathrm{a}}$ ed. Rio de Janeiro: Zahar Editores, 1975.

MOCHCOVITCH, L. G. Gramsci e a escola. $3^{\mathrm{a}}$ ed. São Paulo: Ática, 2001.

MORAES, A. C. GUIMARÃES, E. da F. Metodologia de Ensino de Ciências Sociais: relendo as OCEM - Sociologia. In: BRASIL. Ministério da Educação. Sociologia: ensino médio. Coleção Explorando o Ensino; v. 15. (Coordenação Amaury César Moraes). Brasília, 2010. p. 45-62. Disponível em: < http://portal.mec.gov.br/index.php?option $=$ com_docman\&view $=$ download\&alias $=7843$ 2011-sociologia-capa-pdf\&category_slug=abril-2011-pdf\&Itemid=30192>. Acesso em: 04 jul. 2014.

MORAES, R. Uma tempestade de luz: a compreensão possibilitada pela análise textual discursiva. Ciência \& Educação, v. 9, n. 2, 2003. Disponível em: $<$ http://www.scielo.br/pdf/ciedu/v9n2/04.pdf $>$. Acesso em: 12 jan. 2015.

MORAES, R. GAliaZZI, M. do C. Análise Textual Discursiva. Ijuí: Ed. Unijuí, 2007. 
OLIVEIRA, A. Sentidos e dilemas do ensino de sociologia: um olhar sociológico. Revista Inter-legere. n. 9. jul-dez. 2011. Disponível em: $<$ http://www.cchla.ufrn.br/interlegere/09/inter-legere.htm>. Acesso em: 15 abr. 2015. p. $25-39$.

PASSEGGI, M. da C. A pesquisa (auto)biográfica em educação: princípios epistemológicos, eixos e direcionamentos da investigação científica. In: VASCONCELOS, F.; ATEM, É. (Org.). ALTERidade: o outro como problema. Fortaleza: Expressão Gráfica, 2011, p. 13-39.

PINEAU, G. Experiências de Aprendizagem e Histórias de Vida. In: CARRÉ, P. CASPAR, P. Tratado das Ciências e das Técnicas da Formação. Lisboa: Instituto Piaget, 1999.

. LE GRAND, J-L. As histórias de vida. Natal: EDUFRN, 2012.

RIO GRANDE SO SUL, Secretaria de Educação $-8^{\mathrm{a}}$ CRE. Projeto Político Pedagógico Escola Estadual de Educação Básica Augusto Ruschi. Santa Maria, 2014. Disponível em:

$<$ http://escolaaugustoruschi.com.br/projeto-politico-pedagogico-ppp $>$. Acesso em: 06 jun. 2014.

SANTOS, B. de S. A crítica da razão indolente: contra o desperdício da experiência. 4 ed. São Paulo: Cortez, 2002.

Introdução a uma ciência Pós-moderna. São Paulo: Cortez, 1989.

Um discurso sobre as ciências. $6^{\text {a }}$ ed. São Paulo: Cortez, 2009.

SIMÕES, J. A. GIUMBELLI, E. Cultura e alteridade. BRASIL. Ministério da Educação. Sociologia: ensino médio. Coleção Explorando o Ensino; v. 15. (Coordenação Amaury César Moraes). Brasília, 2010. Disponível em: < http://portal.mec.gov.br/index.php?option $=$ com docman\&view $=$ download\&alias=78432011-sociologia-capa-pdf\&category_slug $=$ abril-2011-pdf\&Itemid=30192>. Acesso em: 04 jul. 2014.

SOUZA, E. C. de. Pesquisa narrativa e escrita (auto) biográfica: interfaces metodológicas e formativas. In: SOUZA, E. C. de. ABRAHÃO, M. H. M. B. (orgs.). Tempos, narrativas e ficções: a invenção de si. Porto Alegre: EDIPUCRS, 2006. p. $135-148$.

VELHO, G. Observando o Familiar In: NUNES, E. de O. A aventura sociológica. Rio de Janeiro: Zahar, 1978. p. 1-13. 


\section{Por uma sociologia da suspensão: da recursividade entre concepções e práticas}

Resumo: Resultado de pesquisa relacionada ao Doutorado em Educação cujo foco é a didática do ensino de Sociologia na escola, o trabalho aborda a imaginação sociológica, o estranhamento e a desnaturalização na relação com as narrativas autobiográficas como dispositivos de formação. Os objetivos foram: pôr em diálogo as orientações curriculares da Sociologia e as narrativas autobiográficas como dispositivos de formação; discutir a fundamentação epistemológica do trabalho com narrativas autorreferenciais nas aulas de Sociologia; apresentar e analisar uma proposta de ensino de Sociologia a partir de narrativas autobiográficas de alunos do $1^{\circ}$ ano do ensino médio. Dialogou-se com os pressupostos da Pesquisa (Auto)biográfica em Educação refletidos com os processos de educação e socialização de Thomas Luckmann, Peter Berger, Charles W. Mills, Pierre Bourdieu e Bernard Lahire. As análises da proposta didática demonstraram que as escritas de si podem gerar estranhamentos e provocar suspensões de saberes e (re)ordenações do mundo se abordadas conjuntamente com os temas sociológicos.

Palavras-chave: Ensino de Sociologia; Pesquisa (Auto)Biográfica em Educação; Educação Básica

\section{For a sociology of suspension: of the recursivity between concepts and practices}

Abstract: Result of research related to Doctorate in Education, whose focus is the didactic teaching of Sociology in school, the work addresses the sociological imagination, the estrangement and the denaturalization in connection with the autobiographical narratives as training methods. The objectives were: put in dialogue the Sociology's curricular orientations and the autobiographical narratives as training methods; debate the work's epistemological foundation with self-referential narratives at the Sociology classes; present and analyse a Sociology teaching proposal starting from the autobiographical narratives of the students from the first year of high school. It was discussed about the concepts of the (Self) Biographic Reasearch in Education that are reflected in the educational and socialization processes of Thomas Luckmann, Peter Berger, Charles W. Mills, Pierre Bourdieu and Bernard Lahire. The analysis of the didactic proposal showed that writing about self could cause estrangements and provoke suspension of knowledge and rearrangement if approached in conjunction with the sociological themes.

Keywords: Teaching of Sociology; Research (Self)Biographic in Education; Basic Education

Recebido em: 18 de agosto de 2015.

Aceito para publicação em: 20 de outubro de 2015 . 